\title{
Experimental Vibration Analysis of a Cracked Laminated Glass Beam with Bolted Joint
}

\author{
Mehmet Yetmez, Serhat Aktas, Ismail Gundogdu, Enes Gur, Emre Karaul, Yagizcan Ulusoy and Hamza Erdogan \\ Department of Mechanical Engineering, Bulent Ecevit University, Zonguldak 67100, Turkey
}

\begin{abstract}
In this study, in order to determine the very early load transfer behavior in the bolted joint connection, experimental dynamic analysis of different laminated glass beams including two surface cracks is considered. For this purpose, both three different plastic interlayers (i.e., three types of polyvinyl butyral_PVB) and three different glass-lamina thicknesses are taken into account. Effects of the plastic interlayer, thickness of the glass-lamina, number of surface cracks and their locations on the vibration characteristics/structural performances are examined experimentally. Vibration tests are performed to present free vibration characteristics of the laminated glass beams under clamped-free boundary conditions. Experimental dynamic analysis consists of six parts: (I) vibration analysis with no-crack and no-hole with a bolted joint; (II) vibration analysis with a surface crack and no-hole with a bolted joint; (III) vibration analysis with two surface cracks and no-hole with a bolted joint; (IV) vibration analysis with no-crack and a hole with a bolted joint; (V) vibration analysis with a surface crack and a hole with a bolted joint; (VI) vibration analysis with two surface cracks and a hole with a bolted joint. For these experimental steps, an impact hammer with a force transducer is used to excite the uncracked or cracked composite beams through the selected points. After the excitation, the responses are obtained by an accelerometer. The vibration measurements are completed using a microprocessor-based data acquisition system and nCode GlyphWorks software. Results are given in tabular and graphical forms.
\end{abstract}

Key words: Vibration, laminated glass beam, PVB, crack, thickness effect.

\section{Introduction}

Many applicable solutions corresponding with the failure analysis for laminated glass components are found in the literature. Under small deflection conditions, experimental evaluations are very reliable. Although higher difference between experimental and mathematical models may be in a very early load range, results are quite acceptable [1]. PVB (polyvinyl butyral) laminated glass is a strong rate-dependent material subjected to both quasi-static and dynamic loading conditions. For the former condition, crack branching increases with increasing quasi-static loading rate. And for the later condition, steady-state cracking speed of PVB laminated glass is lower than that of pure glass [2,3].

The results above are directly related to the

Corresponding author: Mehmet Yetmez, Ph.D., research fields: fracture mechanics and biomechanics. E-mail: yetmez@beun.edu.tr. viscoelastic properties of PVB, especially modulus of rigidity $(G)$. For a general case of a laminated glass beam under bending loading, $G$ plays an important role so that both glass and PVB are assumed to be linear elastic. In addition to the characteristics of PVB, it is noted that its material properties may vary from material to material within the same category [4-8]. Consequently, in order to understand the crack behavior in a laminated glass beam, very early loading condition plays an important role.

In this study, in order to determine the effect of bolted joint connection under very early bending loading, dynamic analysis of different laminated glass beams including two surface cracks is considered. For this purpose, three different polymeric interlayers with three different glass-lamina thicknesses are taken into account. Moreover, thickness of the glass-lamina, number of surface cracks and their locations on the vibration characteristics/structural performances are 
examined experimentally.

\section{Method}

\subsection{Experimental Procedure}

In a similar way of Ref. [1], laminated glass beams are supplied from Dora Automotive Glass Industry and Trade Inc. (Ankara, Turkey). As a standard procedure, all the glass beams including nine specimens with no-hole and nine specimens with a circular hole are manufactured with respect to the condition of 10 bar and $120^{\circ} \mathrm{C}$.

Detailed test setup configurations with a clamped area, place of accelerometer and application of impact hammer are shown in Figs. 1 and 2. All laminated glass beams are $350 \mathrm{~mm}$ in length, $50 \mathrm{~mm}$ in width. Three different lamina thicknesses $(t)$ in Fig. 1 are considered as $3 \mathrm{~mm}, 3.5 \mathrm{~mm}$ and $4 \mathrm{~mm}$. For all the specimens, thickness of PVB interlayer is $0.76 \mathrm{~mm}$. In regards to the interlayer, three main commercial polymeric films of PVB are considered as DUPONTTM $^{\mathrm{TM}}$ (DuPont, USA), S-LEC ${ }^{\mathrm{TM}}$ (Sekisui Chemical Co., Ltd., Japan) and TROSIFOL $^{\circledR}$ (Kurayay Co., Ltd., Japan). Densities of the beam specimens are given in Table 1. For a laminated glass specimen with a bolted joint, the hole diameter $(d)$ is $6 \mathrm{~mm}$ (Figs. 1 and 3).

Two surface cracks with approximately $10 \mathrm{~mm}$ in length, $0.03 \mathrm{~mm}$ in width and $0.02 \mathrm{~mm}$ in depth are created using an oil feed glass cutter (Shanghai Xiangyu Diamond Tools Factory, China). Fig. 3 presents all the damage locations near the end of the beams. All tests are in the very early static loading range of $P$, i.e., dead weight loading: $0 \leq P<7 \mathrm{~N}$ (Fig. 1). For the vibration tests, average impact force of $40 \mathrm{~N}$ is applied near the clamped end for all the laminated glass beams.

On one hand, for the strain measurements in both longitudinal and hoop directions, $3 \mathrm{~mm}$ foil resistance strain gages and an adhesive are used. The FLA-3-50 strain gages (gage factor: $2.1 \pm 0.01$ and gage resistance: $350 \pm 1 \Omega$ ) are products of TML
(Measuring Instruments Laboratory, Co., Ltd., Japan), Tokyo Sokki Kenkyojo Co., Ltd., Japan. The adhesive namely P-2 is also produced by TML, Japan. According to the specimen, the strain gage is mounted at both the center and near the end of the beam (Fig. 3). Then, the 2-channel strain measurements are completed using a microprocessor-based data acquisition system, namely, SoMat eDAQ-lite and SoMat $^{\text {TM }}$ TCE (test control environment) software (SoMat Corporation, HBM Inc., USA).

On the other hand, fundamental natural frequency is measured such that an impact hammer with a force transducer (Model No: 5800B2, Dytran Instruments, Inc., USA) is used to excite the undamaged/damaged laminated glass through the selected point given in

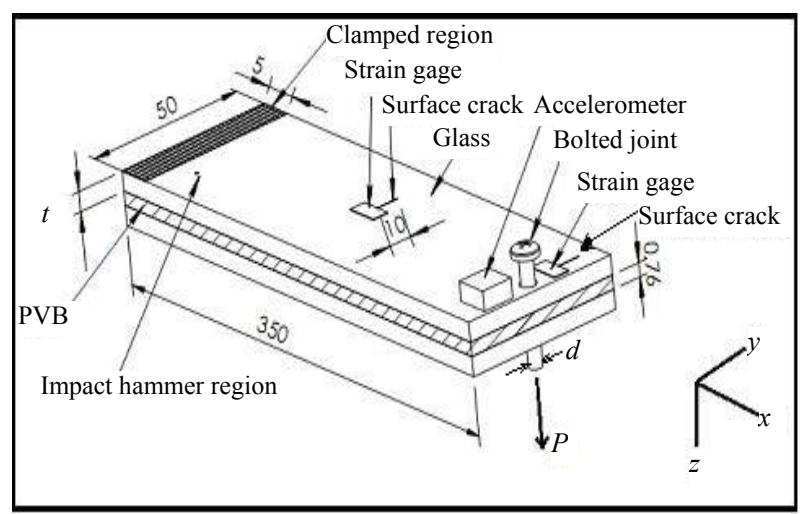

Fig. 1 General representation of laminated glass beam with bolted joint (unit length in $\mathbf{m m}$ ).

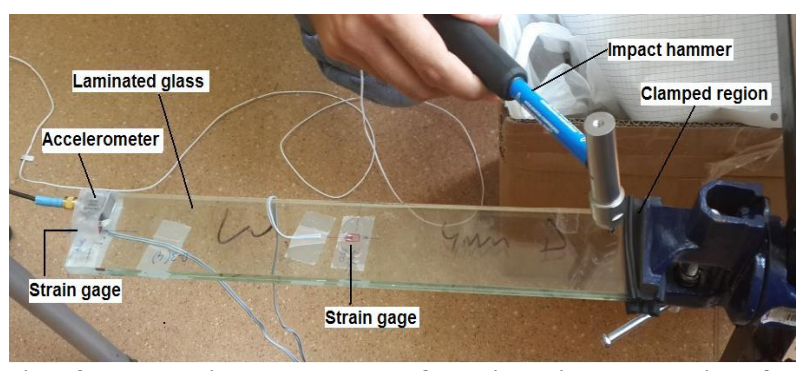

Fig. 2 Experimental setup for vibration analysis of a laminated glass beam.

Table 1 Density values of the laminated glass beams.

\begin{tabular}{llll}
\hline \multirow{2}{*}{$\begin{array}{l}\text { Thickness } \\
(\mathrm{mm})\end{array}$} & \multicolumn{3}{c}{ Density of a laminated glass beam } \\
\cline { 2 - 4 } & $\begin{array}{l}\text { DUPONT } \\
\left(\mathrm{g} / \mathrm{cm}^{3}\right)\end{array}$ & $\begin{array}{l}\text { S-LECTM } \\
\left(\mathrm{g} / \mathrm{cm}^{3}\right)\end{array}$ & $\begin{array}{l}\text { TROSIFOL } \\
\left(\mathrm{g} / \mathrm{cm}^{3}\right)\end{array}$ \\
\hline 3 & 2.35 & 2.35 & 2.36 \\
3.5 & 2.37 & 2.36 & 2.37 \\
4 & 2.4 & 2.38 & 2.38 \\
\hline
\end{tabular}




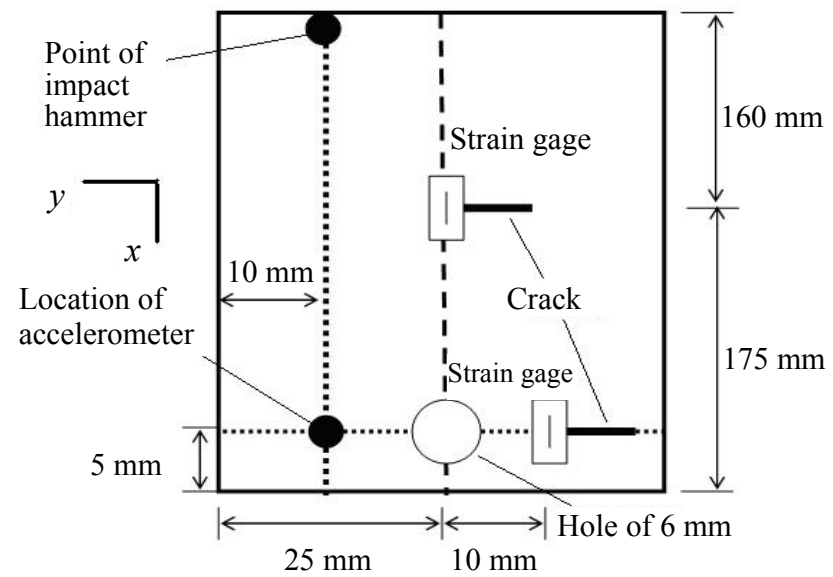

Fig. 3 Damage locations of a laminated glass beam.

Fig. 1. Three impact excitations are applied on the selected application point. After the excitations, the responses are obtained by an accelerometer (Model No: 3093B, Dytran Instruments, Inc., USA). The vibration measurements are completed using a microprocessor-based data acquisition system, namely, SoMat $^{\mathrm{TM}}$ eDAQ-lite and nCode GlyphWorks software (HBM Inc., USA).

An axisymmetic stainless steel bolted-joint with its bolt head and nut is used for this investigation. Mechanical properties of the bolt are as follows: modulus of elasticity, $E_{\text {bolt }}=200 \mathrm{GPa}$; Poisson's ratio, $v_{\text {bolt }}=0.29$ and density, $\rho_{\text {bolt }}=7.89 \mathrm{~g} / \mathrm{cm}^{3}$. During the fixation to a hole of $6 \mathrm{~mm}$ in diameter, two rubber ring joints are also used. Corresponding to the applied very early static load in the range of 0-7 $\mathrm{N}$ and coinciding with the static tests, experimental dynamic analysis consists of six parts: (I) vibration analysis with no-crack and no-hole with a bolted joint; (II) vibration analysis with a surface crack and no-hole with a bolted joint; (III) vibration analysis with two surface cracks and no-hole with a bolted joint; (IV) vibration analysis with no-crack and a hole with a bolted joint; (V) vibration analysis with a surface crack and a hole with a bolted joint; (VI) vibration analysis with two surface cracks and a hole with a bolted joint. For all experiments, values of relative humidity and temperature are in the range of $55 \%-65 \%$ and 26-28 ${ }^{\circ} \mathrm{C}$, respectively.

\subsection{Numerical Procedure}

In order to determine whether the results of experimental stress analysis for a laminated glass beam under bending loading is reliable, a general purpose finite element code, namely, MSC.Marc [9] is put into consideration for the numerical verification. Consequently, under plane stress condition, a two-dimensional course meshed model with four-noded quadrilateral plane element is developed for computing both the strain fields and dynamic characteristics in a simply way.

Therefore, the course meshed model with four-noded quadrilateral plane stress element is analyzed by less than 50,000 elements without any bias factor. Then, a full integration technique is preferred. FEM (finite element modelling) analysis is performed under small strain condition, i.e., $\varepsilon \leq 0.3 \%$. The laminated glass beam is assumed to be linear and elastic for the plane stress finite element analysis $\left(E_{\text {glass beam }}=71.7,67\right.$ and $51.2 \mathrm{GPa}$ for $3,3.5$ and $4 \mathrm{~mm}$ in lamina thickness, respectively). For all beams, Poisson's ratio is assumed to be 0.22 .

\subsection{Analytical Procedure}

Corresponding to the mass of the accelerometer, Eqs. (1) and (2) are considered to compute the Young's modulus for a beam [10]. In Eqs. (1) and (2), $E, I, L, A, m_{a c c}$ and $\omega_{1}$ are Young's modulus, moment of inertia of the plate, length of the plate, cross-sectional area of the plate, mass of the accelerometer and first natural frequency, respectively:

$$
\begin{gathered}
E=\frac{\rho A}{I}\left(\frac{2 \pi \omega_{1}}{\lambda}\right)^{2} \\
\frac{\lambda m_{a c c}}{\rho A}=\frac{1+\cos (\lambda L) \cosh (\lambda L)}{\sin (\lambda L) \cosh (\lambda L)-\cos (\lambda L) \sinh (\lambda L)}
\end{gathered}
$$

\section{Results and Discussions}

In regards to strain field distribution, effects of available cracks and thickness of an unholed laminated glass beam for all three PVB types under 
very early bending loading are presented in Figs. 4-6. It is obvious that, while strain field at the midpoint of the unholed laminated glass beam with no-crack possesses like an exponential distribution, inverse curve distribution appears when a crack (or more) is introduced.

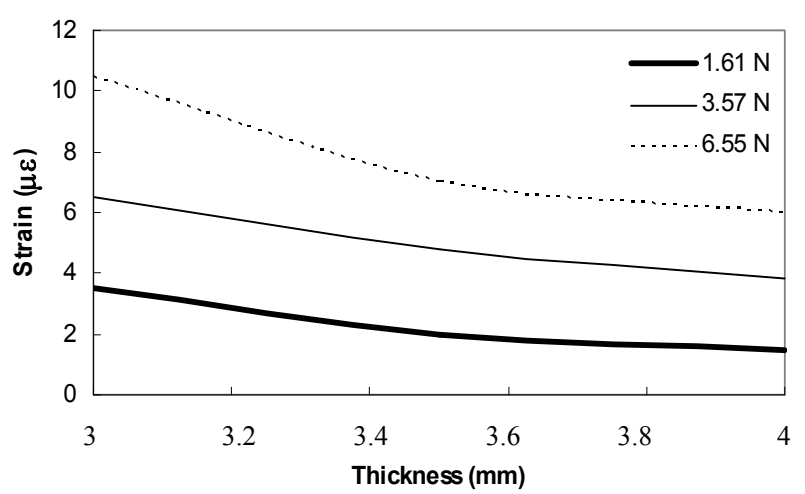

Fig. 4 Variation of strain field at the midpoint of the unholed laminated glass beam with no-crack under very early bending loading.

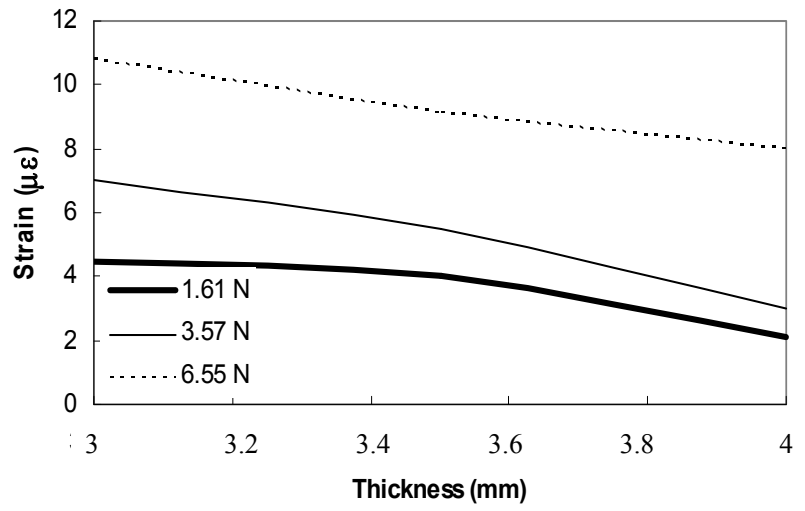

Fig. 5 Variation of strain field at the midpoint of the unholed laminated glass beam with one crack (i.e., crack at the middle of the beam) under very early bending loading.

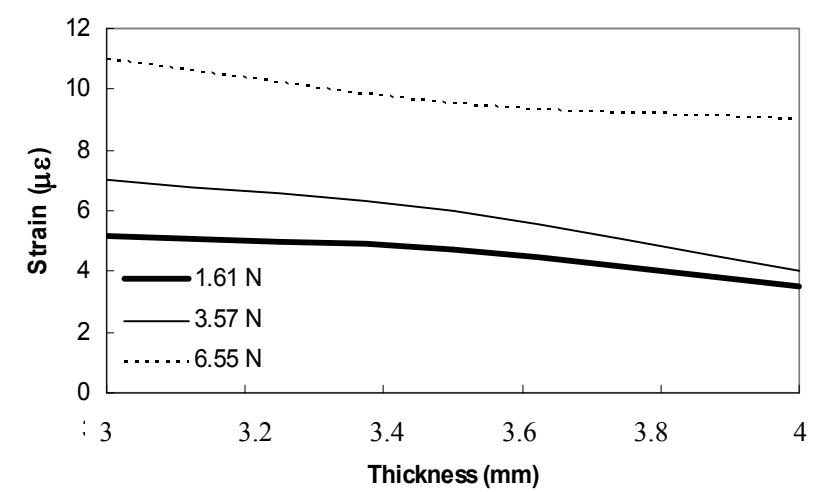

Fig. 6 Variation of strain field at the endpoint of the unholed laminated glass beam with two cracks under very early bending loading.
In Fig. 7, it is obviously shown as an example that strain values of the numerical results are similar with that of the experimental evaluations for an undamaged laminated glass beam (i.e., no-crack and no-hole) with $4 \mathrm{~mm}$ in lamina thickness.

Figs. 8-10 represent the PVB effect on fundamental frequency in $z$-direction for unholed laminated glass beams under no load. On one hand, for all thickness cases, it is noted that increasing the number of cracks decreases the fundamental natural frequency of a laminated glass beam with TROSIFOL ${ }^{\circledR}$. On the other hand, for the interlayer S-LECTM, one may conclude that increasing thickness decreases the crack effect on the natural frequency.

Table 2 gives the comparison of first natural frequencies for the undamaged laminated glass beams of interlayers DUPONT ${ }^{\mathrm{TM}}$ (shortly D), S-LEC ${ }^{\mathrm{TM}}$ (shortly S) and TROSIFOL ${ }^{\circledR}$ (shortly T) with that of the

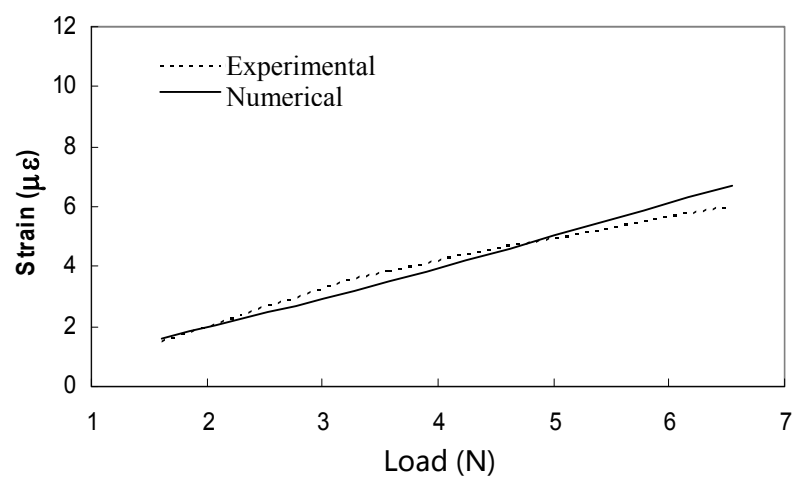

Fig. 7 Comparison of load versus strain behavior for an undamaged laminated glass beam of $4 \mathrm{~mm}$ in lamina-thickness.

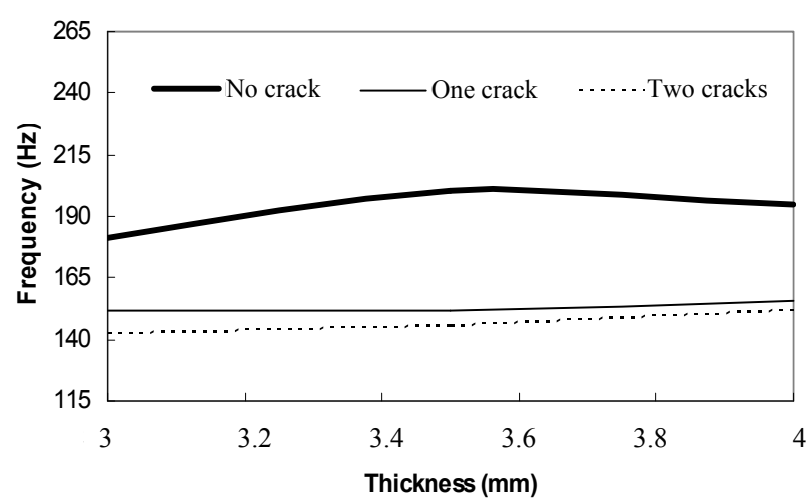

Fig. 8 Variation of fundamental natural frequency with respect to interlayer TROSIFOL ${ }^{\circledR}$ of an unholed laminated glass beam under no load. 


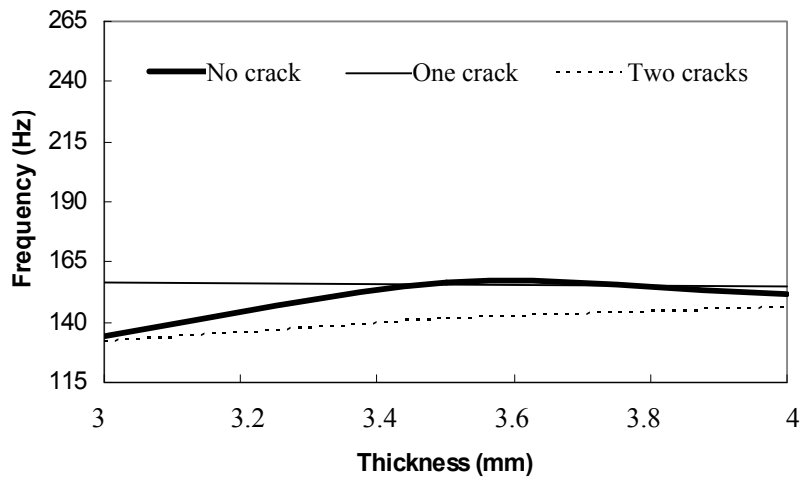

Fig. 9 Variation of fundamental natural frequency with respect to interlayer S-LECTM of an unholed laminated glass beam under no load.

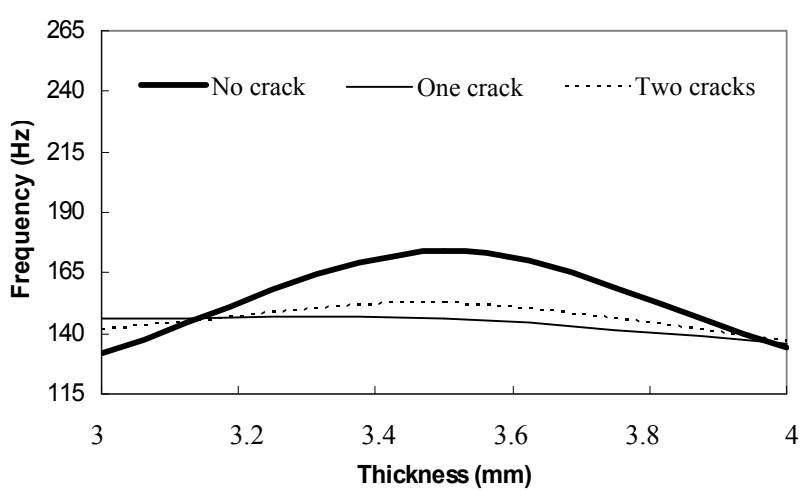

Fig. 10 Variation of fundamental natural frequency with respect to interlayer DUPONT ${ }^{\mathrm{TM}}$ of an unholed laminated glass beam under no load.

Table 2 Comparison of first natural frequencies for the undamaged laminated glass beams of DUPONT'M (D), S-LEC ${ }^{\text {TM }}(S)$ and TROSIFOL ${ }^{\circledR}(T)$ with respect to the analytical results (AR).

\begin{tabular}{lllll}
\hline $\begin{array}{l}\text { Thickness } \\
(\mathrm{mm})\end{array}$ & \multicolumn{4}{c}{ First natural frequency $(\mathrm{Hz})$} \\
\cline { 2 - 5 } & $\mathrm{D}$ & $\mathrm{S}$ & $\mathrm{T}$ & $\mathrm{AR}[10]$ \\
\hline 3 & 186.7 & 190.2 & 181 & 190.1 \\
3.5 & 246.1 & 221.3 & 200 & 210 \\
4 & 190.2 & 214.3 & 195 & 207.4 \\
\hline
\end{tabular}

analytical results (shortly AR). The results indicate that the analytical results coincide with the experimental evaluations.

Figs. 11-13 show the damage effects on fundamental natural frequency for a laminated glass beam with glass lamina thickness of $3 \mathrm{~mm}$ for the interlayer of TROSIFOL ${ }^{\circledR}$ in all coordinates. It is obvious that the major axis for the natural frequency is the $z$-axis and increasing number of crack decreases both the axis- and loading-effect.
In a similar way for the interlayer of S-LEC ${ }^{\mathrm{TM}}$, Figs. 14-16 present the damage effects on fundamental natural frequency for a laminated glass beam with glass lamina thickness of $3 \mathrm{~mm}$ in all coordinates. It is again obvious that the major axis for

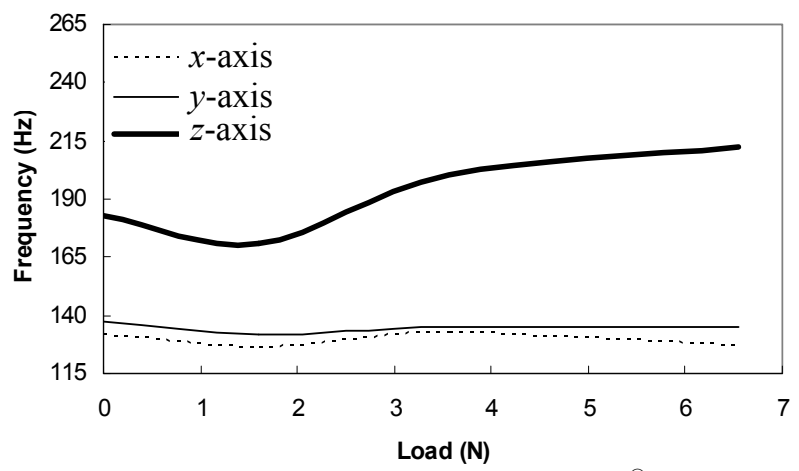

Fig. 11 For the interlayer of TROSIFOL $^{\circledR}$ and glass lamina thickness of $\mathbf{3} \mathbf{~ m m}$, variation of fundamental natural frequency of a laminated glass beam with no-crack and a bolted joint.

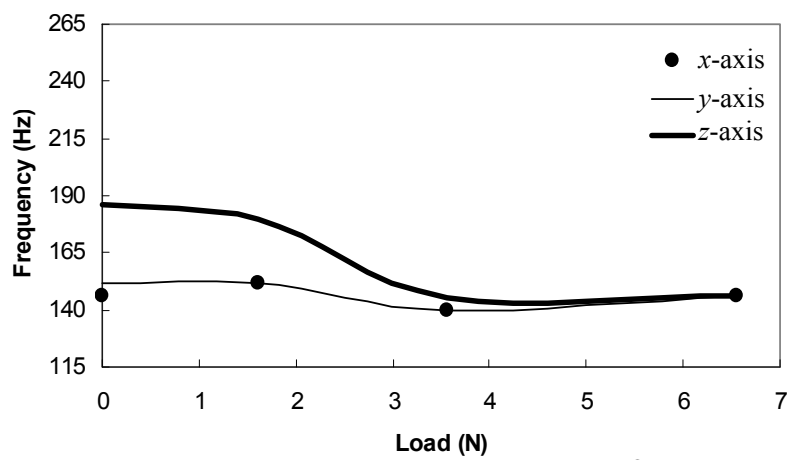

Fig. 12 For the interlayer of TROSIFOL $^{\circledR}$ and glass lamina thickness of $3 \mathbf{~ m m}$, variation of fundamental natural frequency of a laminated glass beam with one crack (i.e., crack at the middle of the beam) and a bolted joint.

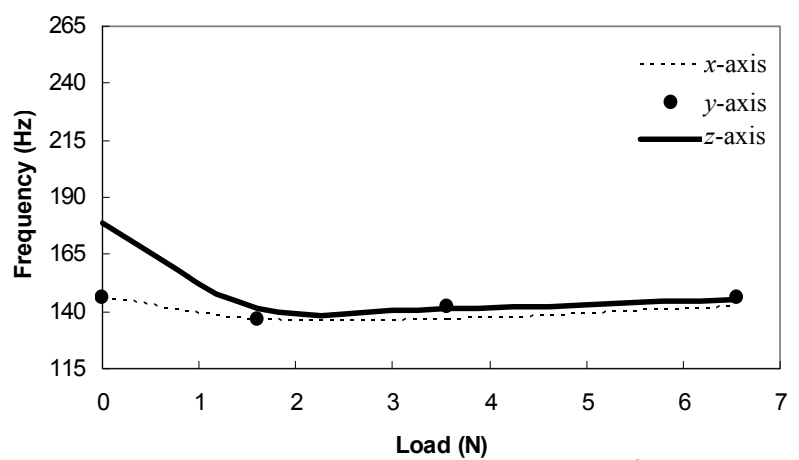

Fig. 13 For the interlayer of TROSIFOL $^{\circledR}$ and glass lamina thickness of $\mathbf{3} \mathbf{~ m m}$, variation of fundamental natural frequency of a laminated glass beam with two cracks and a bolted joint. 


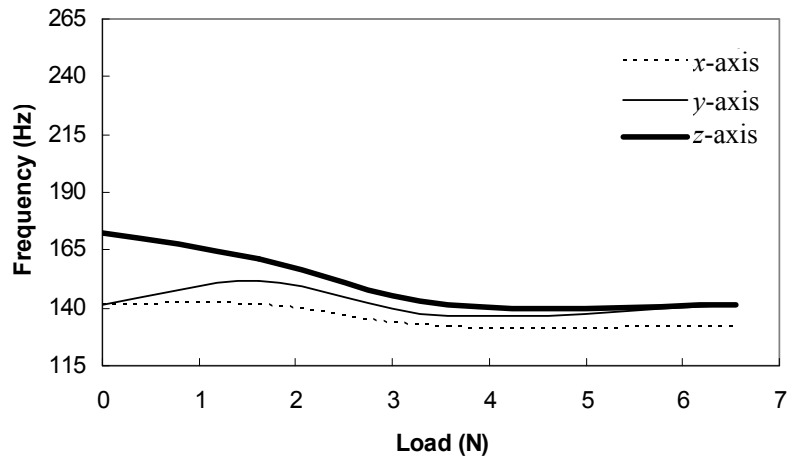

Fig. 14 For the interlayer of S-LEC ${ }^{\text {TM }}$ and glass lamina thickness of $3 \mathrm{~mm}$, variation of fundamental natural frequency of a laminated glass beam with no-crack and a bolted joint.

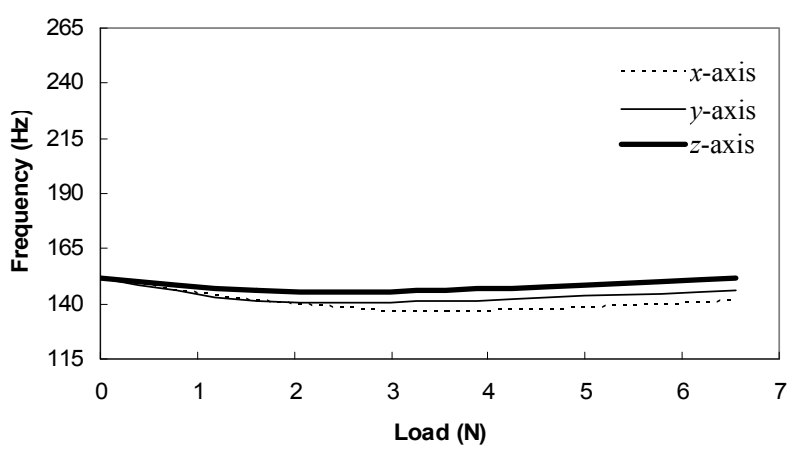

Fig. 15 For the interlayer of S-LEC ${ }^{T M}$ and glass lamina thickness of $3 \mathrm{~mm}$, variation of fundamental natural frequency of a laminated glass beam with one crack (i.e., crack at the middle of the beam) and a bolted joint.

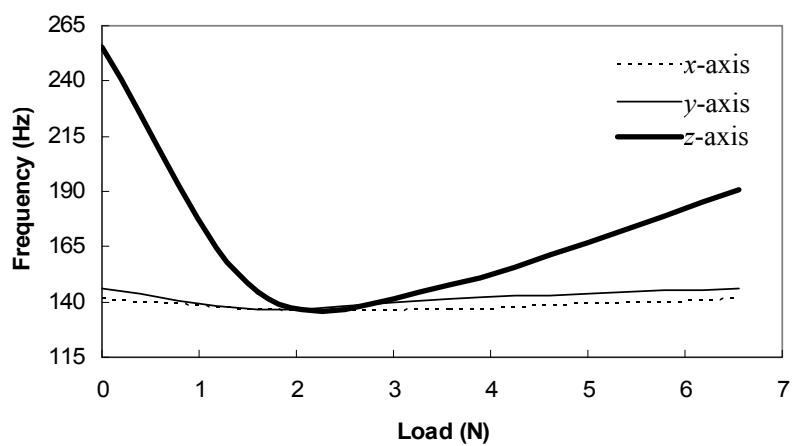

Fig. 16 For the interlayer of S-LEC ${ }^{\mathrm{TM}}$ and glass lamina thickness of $3 \mathrm{~mm}$, variation of fundamental natural frequency of a laminated glass beam with two cracks and a bolted joint.

the natural frequency is the $z$-axis but increasing loading decreases axis-effect for only no-crack case.

At last, for the interlayer of DUPONT ${ }^{\mathrm{TM}}$, Figs. 17-19 view the damage effects on fundamental natural frequency for a laminated glass beam with glass lamina thickness of $3 \mathrm{~mm}$ in all coordinates. It is reobserved that the major axis for the natural frequency is the $z$-axis. From the $x$ - and $y$-axises point of view, increasing number of cracks decreases frequency difference at the beginning loading range. Corresponding to all the three damage cases, when the load is higher than $3 \mathrm{~N}$, fundamental frequencies become closer in all axes.

\section{Conclusions}

In this study, in order to determine the effect of bolted joint connection under very early bending loading, dynamic analysis of different laminated glass beams including two surface cracks is considered. Significant findings are as follows:

(1) Experimental results of undamaged laminated glass beams under early loading $(0-7 \mathrm{~N})$ are compared with the numerical results of the strain field and the analytical results of the first natural frequency. The

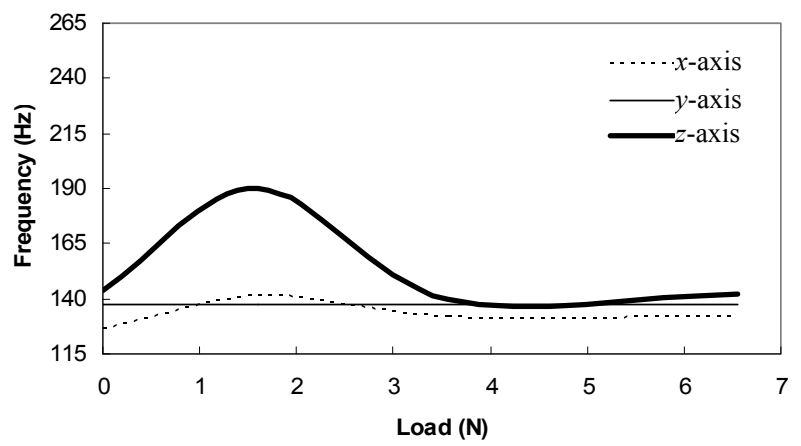

Fig. 17 For the interlayer of DUPONT ${ }^{\mathrm{TM}}$ and glass lamina thickness of $3 \mathrm{~mm}$, variation of fundamental natural frequency of a laminated glass beam with no-crack and a bolted joint.

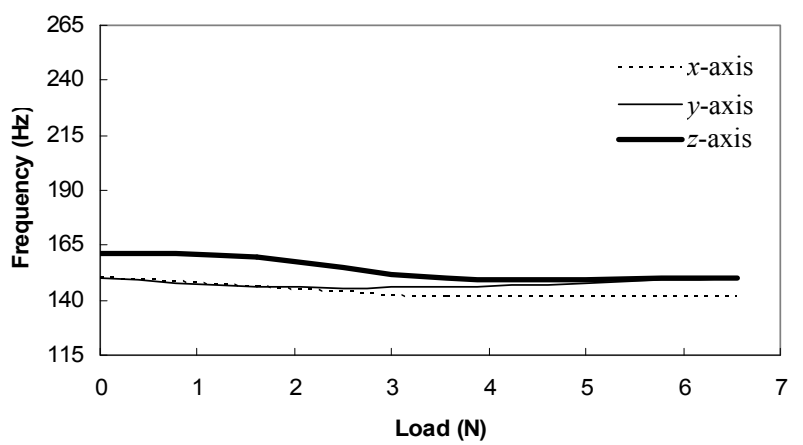

Fig. 18 For the interlayer of DUPONT ${ }^{\mathrm{TM}}$ and glass lamina thickness of $3 \mathrm{~mm}$, variation of fundamental natural frequency of a laminated glass beam with one crack (i.e., crack at the middle of the beam) and a bolted joint. 


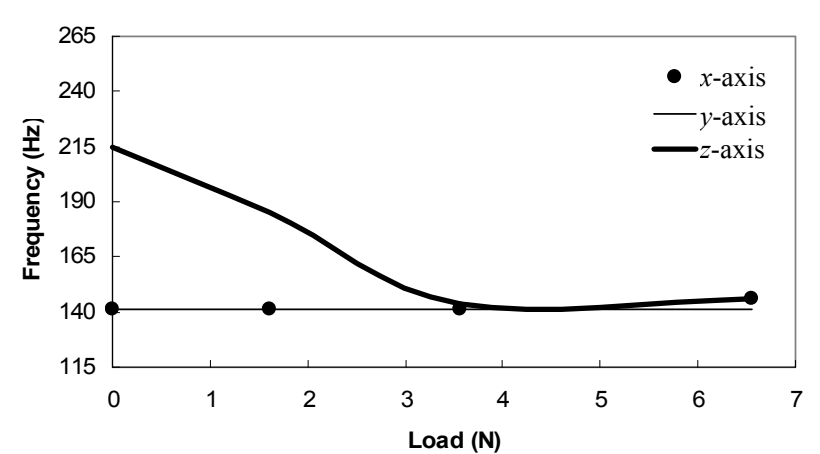

Fig. 19 For the interlayer of DUPONTTM and glass lamina thickness of $3 \mathrm{~mm}$, variation of fundamental natural frequency of a laminated glass beam with two cracks and a bolted joint.

comparisons show that there is a good agreement among them;

(2) According to $x, y$ and $z$ directions, except the laminated glass beam with the interlayer of S-LEC ${ }^{\text {TM, }}$ increasing the damage is found to increase the similarity of curve behavior in load versus first natural frequency graphs. It is recommended for the exception that one may investigate the vibro-acoustic behavior for the damaged laminated glass beams to determine the joint effect clearly;

(3) It is known that transition temperature in the manufacture of a laminated glass varies with each of the different PVB types [11]. For further studies, very low harmonic loading is to be applied on a damaged laminated glass beam under different temperature conditions.

\section{References}

[1] M.Z. Asik, E. Dural, M. Yetmez, T. Uzhan, A mathematical model for the behavior of laminated uniformly curved glass beams, Composites Part B 58B (2014) 593-604

[2] J. Xu, Y. Sun, B. Liu, M. Zhu, X. Yao, Y. Yan, et al., Experimental and macroscopic investigation of dynamic crack patterns in PVB laminated glass sheets subjected to light-weight impact, Engineering Failure Analysis 18 (2011) 1605-1612.

[3] J. Xu, Y. Li, B. Liu, M. Zhu, D. Ge, Experimental study on mechanical behavior of PVB laminated glass under quasi-static and dynamic loadings, Composites: Part B 42 (2011) 302-308

[4] M.Z. Asik, S. Tezcan, A mathematical model for the behavior of laminated glass beams, Computers and Structures 83 (2005) 1742-1753

[5] I.V. Ivanov, Analysis, modeling and optimization of laminated glasses as plane beam, International Journal of Solids and Structures 43 (2006) 6887-6907

[6] L. Galuppi, G. Royer-Carfagni, Laminated beams with viscoelastic interlayer, International Journal of Solids and Structures 49 (2012) 2637-2645

[7] L. Galuppi, G.F. Royer-Carfagni, Effective thickness of laminated glass beams: New expression via a variational approach, Engineering Structures 38 (2012) 53-67.

[8] L. Galuppi, G. Royer-Carfagni, The design of laminated glass under time-dependent loading, International Journal of Mechanical Sciences 68 (2013) 67-75.

[9] Marc Mentat R1 Release, MSC (MacNeal-Schwendler Corporation) Software Corporation, USA, 2008.

[10] Y. Ikei, M. Yamada, S. Fukuda, A new design of haptic texture display-texture display 2- and its preliminary evaluation, in: Proceedings of The IEEE Virtual Reality Annual International Symposium, Japan, 2001, pp. 21-28.

[11] M.Z. Asik, S. Tezcan, Laminated glass beams: Strength factor and temperature effect, Computers and Structures 84 (2006) 364-373. 